\section{Radio Frequency Treatments for Postharvest Codling Moth Control in Fresh Apples}

\author{
J.D. Hansen ${ }^{1}$, S.R. Drake ${ }^{2}$, \\ M.L. Heidt ${ }^{1}$, M.A. Watkins ${ }^{1}$, \\ J. Tang ${ }^{3}$, and S. Wang ${ }^{3}$
}

Additional index words. Cydia pomonella, heat treatment, quarantine

SUMMARY. Efficacy of using radio frequency (RF) at $27.12 \mathrm{MHz}$ was evaluated as a postharvest quarantine treatment against fifth instars of the codling moth [Cydia pomonella (Lepidoptera: Tortricidae)], in apples ( $M a-$ lus sylvestris). Tests under the given conditions demonstrated that the energy fields between the RF unit's electrodes were neither predictable nor uniform. Moving fruit submerged in water during RF exposure may improve uniformity, but pulp temperatures varied considerably among fruit, among sites on the same fruit, and at different depths within the same site. As a result of these inconsistencies, quarantine efficacy was not obtained either using a range of final average temperatures from 40 to $68^{\circ} \mathrm{C}(104.0$ to $154.4{ }^{\circ} \mathrm{F}$ ) or at holding times up to 20 minutes. We concluded it would be difficult to obtain the appropriate parameters for treatment efficacy and fruit quality maintenance using this technology under these conditions.

${ }^{1}$ USDA-ARS-YARL, 5230 Konnowac Pass Rd., Wapato, WA 98951.

${ }^{2}$ USDA-ARS-TFRL, 1104 N. Western Ave., Wenatchee, WA 98801 .

${ }^{3}$ Department of Biological Systems Engineering, Washington State University, Pullman, WA 99164

Acknowledgments. We are grateful to the following for their support: J. Weenink, T. Gorrebeeck, G. Scaife and D. Hallauer (ARS, Wapato, Wash.); J. Archer and F. Scarlett (Northwest Fruit Exporters, Yakima, Wash.). We thank Tony Koral (Strayfield Fastran, Wokingham, U.K.) for his advice and recommendations The manuscript was reviewed by P. Landolt (ARS, Wapato), E. Curry (ARS, Wenatchee, Wash.), and G. Hallman (ARS, Weslaco, Texas). Partial funding for this research was from the Washington Tree Fruit Research Commission.Mention of a proprietary product does not constitute an endorsement or recommendation by USDA for its use.
A pples exported to Japan must meet quarantine security. The codling moth is a pest of concern [Ministry of Agriculture, Forestry and Fisheries-Japan (MAFF-Japan), 1950]. The currently approved procedure is a combination of cold storage followed by methyl bromide fumigation (Hansen et al., 2000; Moffitt et al., 1988). However, because methyl bromide has been identified as an agent that depletes ozone by the U.S. Environmental Protection Agency (U.S. Congress, 1990) and the Montreal Protocol (United Nations Environmental Program, 1995), its continued use in quarantine treatments is in question. Methyl bromide currently has an exemption for postharvest quarantine use, but its cost is increasing.

Among the alternatives to methyl bromide fumigation (irradiation, controlled atmosphere, cold, other chemicals), heat treatments have generated the most interest. Yokoyama et al. (1991) measured codling moth mortality in the egg and larval stages exposed to 45 to $51{ }^{\circ} \mathrm{C}\left(113.0\right.$ to $\left.123.8{ }^{\circ} \mathrm{F}\right)$ for different durations. Neven (1994) examined mortality of fifth instar codling moth after heat treatments of 43 to $45^{\circ} \mathrm{C}\left(109.4\right.$ to $\left.113.0^{\circ} \mathrm{F}\right)$ followed by cold storage for 0 to $5^{\circ} \mathrm{C}$ (32.0 to $\left.41.0^{\circ} \mathrm{F}\right)$. Jones and Waddell (1997) directly submerged codling moth eggs and larvae in 43 to $49^{\circ} \mathrm{C}(109.4$ to $120.2^{\circ} \mathrm{F}$ ) water baths for various durations and determined their survival rates. Thermal death kinetics of codling moth larvae were further evaluated by the use of a unique heating block system (Tang et al., 2000; Wang et al., 2002a, 2002b).

An innovative method of heating is to use radio frequency (RF) energy, which has longer wavelengths than microwaves. This is done by dielectric heating generated from internal resistance to very rapid alterations of polarity (Headlee and Jobbins, 1936). Three radio frequencies have been allocated by the U.S. Federal Communications Commission for industrial use: 13.56 $\pm 0.067,27.12 \pm 0.160$, and 40.68 $\pm 0.020 \mathrm{MHz}$ (Wang et al., 2001). This technology seems attractive for postharvest application in that heating is fast and linear with time, energy can penetrate deep into the commodity, there are no chemical residues, and the process has minimal impact on the environment (Tang et al., 2000). RF treatments show promise in control- ling stored product pests of walnuts (Juglans regia) (Wang et al., 2001, $2002 \mathrm{~b}$ ). A saline water immersion with RF exposure may be more feasible for fruit (Ikediala et al., 2002).

Because RF has not been used as a postharvest treatment to control codling moth in apples, our objectives were to determine the temperature uniformity in water loads and to examine the utility of such technology for postharvest quarantine control.

\section{Materials and methods}

EXPERIMENTAL UNIT. Experiments were conducted using a 12-kW Fastran RF heater/dryer with an E-200 control panel (Strayfield International Ltd., Wokingham, U.K.), with the frequency set at 27.12 MHz. The interior of the unit's cavity consisted of two 104.775 $\mathrm{cm}(41.25$ inches $) \times 79.375 \mathrm{~cm}(31.25$ inches) electrodes; the bottom one was stationary whereas the top one could be elevated from $20 \mathrm{~cm}$ ( 7.9 inches) to $40 \mathrm{~cm}$ ( 15.7 inches) above the bottom electrode. The top electrode could be tuned by adjusting the inductance through the lengths of three interconnected parallel metal plates above it, thereby changing slightly the strength of the energy field.

Energy was induced between the electrodes by a high-energy RF oscillator (Tang et al., 2000; Wang et al., $2001)$. The amount of power coupled by the target material (tap water) was linearly related to the induced electrical current following the equation according to the user manual:

$$
w=-1.8+7.1 i
$$

where $w$ is power in $\mathrm{kW}$ and $i$ is amperage. Because the unit was rated at 12 $\mathrm{kW}$, maximum electrical current was at 2 amps. The power applied to the target material was adjusted by lowering or raising the top electrode, changing the dimensions of the target, and by varying the amount of mass (load) to meet the other conditions. Treated material was restricted to vegetable matter, water, glass, and most plastics. Metal would cause arcing between the electrodes, and nylon would melt.

UNIFORMITY TESTS. Energy generated between electrodes might be not uniformly distributed. Because unequal energy distribution would cause differential heating on the targeted material, thereby preventing the development of effective heat treatments, three types of tests were conducted to map the energy 
fields in relation to the electrodes.

In the first test, two plastic racks, $48 \mathrm{~cm}$ long $\times 48 \mathrm{~cm}$ wide $\times 10.5 \mathrm{~cm}$ high $(18.9 \times 18.9 \times 4.13$ inches $)$, were placed side-by-side. A plastic grid $0.84 \mathrm{~cm}(0.3$ inch $)$ thick with $1.27-\mathrm{cm}(0.5 \mathrm{inch})$ squared spaces and $0.1-\mathrm{cm}(0.04$ inch) ribbing was put on top of the racks. Then a highdensity polyethylene foam mat, 91.4 $\mathrm{cm}$ wide $\times 121.9 \mathrm{~cm}$ long $\times 10.2 \mathrm{~cm}$ thick (36 $\times 48 \times 4$ inches), was placed on top of the grid. The mat was divided into 24 equal sections, four rows $\times$ six columns. Before each treatment, the foam was saturated with tap water at $\sim 20^{\circ} \mathrm{C}\left(68.0^{\circ} \mathrm{F}\right)$. The duration of each treatment was $10 \mathrm{~min}$ and generated $0.4 \mathrm{amps}$, and these treatments were replicated 15 times. After treatment, the temperature of each section $5.1 \mathrm{~cm}$ ( 2 inches) deep was measured using a portable VWR Traceable Digital Thermometer (Control Co., Friendswood, Texas) with $+/-0.05{ }^{\circ} \mathrm{C}\left(0.090{ }^{\circ} \mathrm{F}\right)$ accuracy using a $15.2-\mathrm{cm}$ (6 inches) probe designed for liquids and listed reading rate as four times per second. Temperature of the water-saturated foam returned to $\sim 20{ }^{\circ} \mathrm{C}$ before additional treatments.

In the second test, 946- $\mathrm{mL}(\mathrm{l} \mathrm{qt})$ glass jars, $16.51 \mathrm{~cm}$ (6.5 inches) high and $8.89 \mathrm{~cm}(3.5$ inches $)$ in diameter, were arranged in a $5 \times 4$ grid evenly distributed on the lower electrode. Initial water temperature was $\sim 20^{\circ} \mathrm{C}$. Treatments were conducted five times for $5 \mathrm{~min}$, reaching $2 \mathrm{amp}$ for each run. Water temperatures were measured as in the previous test.

The third test used 3.8- $\mathrm{L}$ ( 1 gal) glass jars, $16 \mathrm{~cm}$ ( 6.3 inches) high and $14.5 \mathrm{~cm}$ (5.71 inches) in diameter, were arranged in a $5 \times 4$ grid similar to the second test. Initial water temperature was $\sim 20^{\circ} \mathrm{C}$. Each of the three runs was for $10 \mathrm{~min}$ and obtained $2 \mathrm{amp}$. Water temperatures were measured as before.

Treatment OF MOVING FRUIT. One way to compensate for energy nonuniformity is to move the fruit. Birla et al. (2004) used a specially constructed polypropylene square container with water to move fruit during RF treatments. We built our apple mover using commercial parts. The holding tank was a round 94.6-L (25 gal) low-density polyethylene tub (Konnex Plastics, La Mirada, Calif.), $33.0 \mathrm{~cm}$ (13 inches) high with an upper $67.31 \mathrm{~cm}(26.5$ inches $)$ i.d. and a
$61.0 \mathrm{~cm}$ (24 inches) loweri.d. Polyvinyl chloride piping connected the tub to a two-speed, 1.5-horsepower Century Lasar Pool/Spa Motor Pump (Aquaflo Inc., Chino, Calif.) located outside the unit. The piping consisted of inflow and out-flow lines attached to the side of the tub, and a nozzle below the surface to direct the water flow. Apples were submerged using a plastic grid made of the same material as the grid used with the foam mat, with two 33.0 -cm ceramic square tiles, $0.635 \mathrm{~cm}$ (0.25 inch) thick, to provide weight. The fruit would circulate around the tub about six times in a minute.

Extensive testing was done using size 100 Washington Extra Fancy 'Delicious' apples, obtained from commercial sources in Washington state, to determine the treatment parameters needed to heat the fruit to within the temperature range considered lethal (Wang et al., 2002a) while operating the unit at a maximum power (2 amp). The best combination of treatment specifications was to use 40 fruit removed from $4{ }^{\circ} \mathrm{C}\left(39.2{ }^{\circ} \mathrm{F}\right)$ cold storage, then placed in $\sim 24{ }^{\circ} \mathrm{C}(75.2$ $\left.{ }^{\circ} \mathrm{F}\right)$ tap water with a 10 -min exposure. Treatments were rejected that were interrupted by arcing or had an obvious burning smell. After treatment, a fruit was selected at random and 24 temperature measurements taken at two depths, $1 \mathrm{~cm}(0.4$ inch $)$ and $2 \mathrm{~cm}(0.8$ inch), along four perpendicular axes from the stem to the calyx midpoint at the top and bottom and along the equator. Thus, there were the same numbers of measurements on either half of the fruit taken at the same depths. Temperatures were measured using a portable digital thermometer (model HH501DK; Omega Engineering Inc., Stamford, Conn.) equipped with a k-type thermocouple and the response time listed as $0.8 \mathrm{~s}$. Tests were replicated five times.

EFFICACY TESTS. Codling moth larvae were obtained from the colony reared at the USDA-ARS-YARL facility (Wapato, Wash.), where they were maintained on a soy-wheat germ-starch artificial diet at $\sim 27{ }^{\circ} \mathrm{C}$ $\left(80.6{ }^{\circ} \mathrm{F}\right), 40 \%$ to $58 \%$ relative humidity $(\mathrm{RH})$, with a $16 \mathrm{~h}$ light $/ 8 \mathrm{~h}$ dark photoperiod (Toba and Howell, 1991). Previous tests established that the fifth instar codling moth is the larval stage most tolerant to heat (Wang et al., 2002a). Therefore, late fourth to early fifth instars were removed from artificial diet and four larvae were directly placed at the stem end of each apple, as was done for previous tests approved by MAFF-Japan (Hansen et al., 2000). Late fifth instars were excluded because they would form cocoons for pupation instead of feeding. Infested apples were held overnight (12-18 h) at $\sim 24{ }^{\circ} \mathrm{C}, 60 \%$ to $70 \% \mathrm{RH}$, with a $16 \mathrm{~h}$ light $/ 8 \mathrm{~h}$ dark photoperiod, then treated as previously described, varying only the exposure time. Forty apples were divided into four groups consisting of nine infested fruit plus an uninfested fruit used for temperature monitoring. To reduce the effects of unequal heating, the groups of fruit were held in the tub after RF exposure; the first group was removed 5 min after treatment with the remaining removed sequentially, also after 5 -min periods, with $20 \mathrm{~min}$ as the longest holding time. With each group removal, pulp temperatures of the monitor apple were taken at the same 24 sites as before. After hydrocooling in a cold water [ 10 $\left.{ }^{\circ} \mathrm{C}\left(50.0^{\circ} \mathrm{F}\right)\right]$ bath to reach ambient temperature, the infested fruit were held overnight at $\sim 24^{\circ} \mathrm{C}$. Treated fruit were evaluated the next day by dissecting the fruit and recording the number of live and dead larvae. Unresponsive larvae were considered dead.

Data ANALYsis. Means and standard deviations were calculated using Quattro Pro version 7 spreadsheet software (Corel Corp. Ltd., Orem, Utah). Data were analyzed using SAS (SAS Institute, Cary, N.C.); PROC MEANS was used for univariate statistics, and nonparametric tests were used to determine significant differences by first arranging data by PROC RANK, then performing PROC GLM. This approach is equivalent to a Wilcoxon rank sum test for two samples and the Kruskal-Wallis $k$-sample test for more than two samples (Zolman, 1993). TableCurve 2D version 5.01 (SYSTAT Software Inc., Richmond, Calif.) was used to screen more than 8100 mathematical models to describe the relationship of fruit temperature at the two pulp depths and the decline of fruit temperature over time.

\section{Results}

UNIFORMITY TESTS. In the foam test, the rear left areas tended to be warmer than the front right portion (Table 1). Highest temperature was $63.5^{\circ} \mathrm{C}\left(146.30^{\circ} \mathrm{F}\right)$ at the left rear corner whereas the coldest was 21.5 
${ }^{\circ} \mathrm{C}\left(70.70^{\circ} \mathrm{F}\right)$ in the middle toward the rear. Largest range of temperatures (the difference between the hottest and coldest) was $40.3{ }^{\circ} \mathrm{C}\left(72.54{ }^{\circ} \mathrm{F}\right)$ at the left rear corner, which had the highest average temperature of $42.2{ }^{\circ} \mathrm{C}$ $\left(107.96^{\circ} \mathrm{F}\right)$. Smallest range of temperatures was 16.6 ${ }^{\circ} \mathrm{C}\left(29.88^{\circ} \mathrm{F}\right)$ at the right front corner, which had the lowest average temperature of $33.1{ }^{\circ} \mathrm{C}\left(91.58^{\circ} \mathrm{F}\right)$.

Temperature pattern differed with the water jars. In the smaller glass jar tests, the warmest temperatures tended to be on the right side whereas the coldest temperatures were in the middle (Table 2). The highest temperature was $61.9^{\circ} \mathrm{C}\left(143.42^{\circ} \mathrm{F}\right)$ at the right rear corner whereas the coldest was $43.2^{\circ} \mathrm{C}$ $\left(109.76{ }^{\circ} \mathrm{F}\right)$ in the middle toward the front. Largest range of temperatures was $10.4^{\circ} \mathrm{C}\left(18.72^{\circ} \mathrm{C}\right)$ in the first two rows towards the middle whereas the smallest range was $2.1{ }^{\circ} \mathrm{C}\left(3.78{ }^{\circ} \mathrm{F}\right)$ in the middle toward the rear. Highest average temperature was $57.9^{\circ} \mathrm{C}$ $\left(136.22^{\circ} \mathrm{F}\right)$ at the right rear corner and lowest average temperature was $49.6{ }^{\circ} \mathrm{C}\left(121.28^{\circ} \mathrm{F}\right)$ in the middle toward the front.

Similar observations were made with the 1-gal glass jars (Table 3 ). Highest temperature was $47.8{ }^{\circ} \mathrm{C}$ $\left(118.04{ }^{\circ} \mathrm{F}\right)$ next to the right rear corner whereas the coldest was 31.5 ${ }^{\circ} \mathrm{C}\left(88.70{ }^{\circ} \mathrm{F}\right)$ in the front toward the right, which also had the largest range of temperatures at $11.5{ }^{\circ} \mathrm{C}(20.70$ $\left.{ }^{\circ} \mathrm{F}\right)$. Smallest range was $1.8^{\circ} \mathrm{C}(3.24$ ${ }^{\circ} \mathrm{F}$ ) in the middle toward the left rear. Highest average temperature was 45.6 ${ }^{\circ} \mathrm{C}\left(114.08^{\circ} \mathrm{F}\right)$ at the right rear corner and the lowest average temperature was $35.8^{\circ} \mathrm{C}\left(96.44^{\circ} \mathrm{F}\right)$ in the middle toward the front.

Moving FRUIT. Temperatures of the moving fruit (Fig. 1) were significantly different among the replicates $(F=38.77 ; \mathrm{df}=4,115 ; P<0.01)$. The third replicate was the coldest, with the average temperature among the measured sites at $45.2^{\circ} \mathrm{C}(113.36$ $\left.{ }^{\circ} \mathrm{F}\right)$ and the hottest at $63.8^{\circ} \mathrm{C}(146.84$ $\left.{ }^{\circ} \mathrm{F}\right)$. The range between the coldest and the hottest temperatures was 27.2 ${ }^{\circ} \mathrm{C}\left(48.96{ }^{\circ} \mathrm{F}\right)$. In all replicates, the $1-\mathrm{cm}$ temperatures were lower than the deeper measurements. Standard deviations per test ranged from 1.9
Table 2. The mean \pm SD of water temperatures $\left({ }^{\circ} \mathrm{C}\right)^{\mathrm{z}}$ measured horizontally from twenty $946-\mathrm{mL}(1 \mathrm{qt})$ glass jars exposed for $5 \mathrm{~min}$ in a $27.12 \mathrm{MHz}$ radio frequency unit at 2.0 amps; $n=5$. Row 1 at the front and row 4 at the back of the unit; column A on the far left and column $\mathrm{E}$ on the far right.

\begin{tabular}{cccccc}
\hline & \multicolumn{5}{c}{ Back } \\
\cline { 2 - 6 } Column & A & B & C & D & E \\
\hline Row 4 & $50.7 \pm 1.2$ & $50.7 \pm 2.4$ & $53.2 \pm 3.7$ & $55.0 \pm 2.1$ & $57.9 \pm 3.1$ \\
3 & $52.0 \pm 1.7$ & $53.0 \pm 1.2$ & $47.9 \pm 2.4$ & $53.9 \pm 0.7$ & $56.1 \pm 3.4$ \\
2 & $50.0 \pm 2.1$ & $50.7 \pm 3.1$ & $49.6 \pm 3.9$ & $54.1 \pm 3.0$ & $56.2 \pm 3.9$ \\
1 & $50.5 \pm 1.9$ & $51.8 \pm 3.6$ & $52.2 \pm 2.4$ & $53.7 \pm 2.3$ & $56.8 \pm 3.8$ \\
\cline { 2 - 6 } & \multicolumn{5}{c}{ Front } \\
\hline${ }^{2 \circ} \mathrm{F}=1.8\left({ }^{\circ} \mathrm{C}\right)+32^{\circ}$ & &
\end{tabular}

Table 3. The mean $( \pm \mathrm{SD})$ of water temperatures $\left({ }^{\circ} \mathrm{C}\right)^{\mathrm{z}}$ measured horizontally from twenty 3.8-L (1 gal) glass jars exposed for $10 \mathrm{~min}$ in a $27.12 \mathrm{MHz}$ radio frequency unit at 2.0 amps; $n=3$. Row 1 at the front and row 4 at the back of the unit; column A on the far left and column $\mathrm{E}$ on the far right.

\begin{tabular}{|c|c|c|c|c|c|c|}
\hline \multirow{2}{*}{\multicolumn{2}{|c|}{ Column }} & \multicolumn{5}{|c|}{ Back } \\
\hline & & A & B & $\mathrm{C}$ & $\mathrm{D}$ & $\mathrm{E}$ \\
\hline \multirow[t]{4}{*}{ Row } & 4 & $41.5 \pm 2.0$ & $39.0 \pm 0.8$ & $40.7 \pm 1.9$ & $44.4 \pm 0.8$ & $45.6 \pm 2.2$ \\
\hline & 3 & $40.4 \pm 1.3$ & $40.4 \pm 0.8$ & $35.8 \pm 1.1$ & $38.4 \pm 1.6$ & $44.7 \pm 3.6$ \\
\hline & 2 & $39.3 \pm 1.2$ & $37.5 \pm 2.9$ & $35.8 \pm 1.3$ & $37.7 \pm 1.8$ & $42.4 \pm 1.6$ \\
\hline & 1 & $39.4 \pm 1.3$ & $38.5 \pm 2.5$ & $37.7 \pm 2.1$ & $37.6 \pm 4.7$ & $43.5 \pm 2.2$ \\
\hline
\end{tabular}

\footnotetext{
${ }^{\circ} \mathrm{F}=1.8\left({ }^{\circ} \mathrm{C}\right)+32^{\circ}$
}

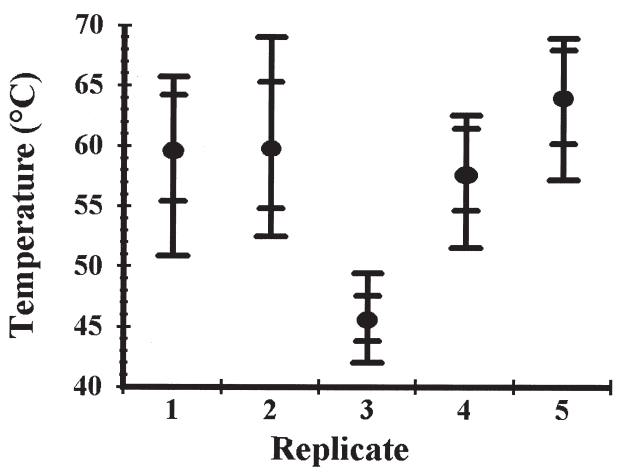

Fig. 1. The mean (filled circle), standard deviation (inside bar), and range (outside bar) of pulp temperatures taken at depths of 1 and $2 \mathrm{~cm}$ ( 0.4 and 0.8 inch) from 24 evenly distributed sites on each monitored apple of five replicates treated while circulating in a water bath for $10 \mathrm{~min}$ while exposed to $2 \mathrm{amp}$ in the $27.12 \mathrm{MHz}$ radio frequency unit. ${ }^{\circ} \mathrm{F}=1.8\left({ }^{\circ} \mathrm{C}\right)+32^{\circ}$. 
to $3.4{ }^{\circ} \mathrm{C}\left(3.42\right.$ to $\left.6.12{ }^{\circ} \mathrm{F}\right)$ for $1 \mathrm{~cm}$ and from 1.6 to $2.2^{\circ} \mathrm{C}(2.88$ to 3.96 ${ }^{\circ} \mathrm{F}$ ) for $2 \mathrm{~cm}$. Average \pm SD temperatures at the $1-\mathrm{cm}$ depth for all tests were lower, $54.0 \pm 5.7{ }^{\circ} \mathrm{C}(129.20$ $\left.\pm 10.26^{\circ} \mathrm{F}\right)$, than at the $2 \mathrm{~cm}$ depth, $60.2 \pm 7.7^{\circ} \mathrm{C}\left(140.36 \pm 13.86^{\circ} \mathrm{F}\right)$. Average \pm SD difference between both depths for all measurements was 6.2 $\pm 3.4^{\circ} \mathrm{C}\left(11.16 \pm 6.12^{\circ} \mathrm{F}\right)$. Greatest temperature difference between the two depths measured at the same site was $12.7^{\circ} \mathrm{C}\left(22.86^{\circ} \mathrm{F}\right)$ from the first replicate for the deeper depth having the greater value and $0.7^{\circ} \mathrm{C}(1.26$ ${ }^{\circ} \mathrm{F}$ ) from the fourth replicate for the upper depth having the greater value. Linear relationship between the two depths for all measurements was $T_{1 \mathrm{~cm}}$ $=0.682 T_{2 c m}+13.0{ }^{\circ} \mathrm{C}\left(r^{2}=0.828\right)$. The results suggested that there was a temperature reduction from the fruit center to the surface because of less energy absorption in tap water than in the fruit. Neither the longitudinal axes nor the latitudinal ring consistently showed uniquely hot areas for either depth among any of the replicates under the given conditions.

EFFICACY TESTS. Temperature conditions of the fruit changed with time. Average \pm SD fruit temperature at $2 \mathrm{~cm}$ decreased with holding time for 5 min: $58.0 \pm 9.0^{\circ} \mathrm{C}(136.40 \pm 16.20$ $\left.{ }^{\circ} \mathrm{F}\right), 10$ min: $51.8 \pm 7.0{ }^{\circ} \mathrm{C}(125.24$ $\left.\pm 12.60{ }^{\circ} \mathrm{F}\right), 15 \mathrm{~min}: 48.5 \pm 4.9^{\circ} \mathrm{C}$ $\left(119.30 \pm 8.82^{\circ} \mathrm{F}\right)$, and $20 \mathrm{~min}: 48.3$ $\pm 4.6^{\circ} \mathrm{C}\left(118.94 \pm 8.28^{\circ} \mathrm{F}\right)$. The equation that best $\left(r^{2}=0.281\right)$ described this decline in temperature was:

$$
y=a+b \mathrm{e}^{(-x / c)}
$$

where $a=47.4{ }^{\circ} \mathrm{C}\left(117.37{ }^{\circ} \mathrm{F}\right), b=$ $27.6^{\circ} \mathrm{C}\left(49.60^{\circ} \mathrm{F}\right), c=5.25, x$ is time in minutes, and $y$ is average temperature at $2-\mathrm{cm}$ depth for time $x$.

Efficacy of the treatment increased with final fruit temperature at $2 \mathrm{~cm}$ and with holding time (Fig. 2). Total mortality of the treated larval population was obtained at $50^{\circ} \mathrm{C}\left(122.0^{\circ} \mathrm{F}\right)$ for $20 \mathrm{~min}, 57^{\circ} \mathrm{C}\left(134.6^{\circ} \mathrm{F}\right)$ for 10 $\mathrm{min}$, and $67^{\circ} \mathrm{C}\left(152.6^{\circ} \mathrm{F}\right)$ for $5 \mathrm{~min}$. However, survivors were observed after $20 \mathrm{~min}$ at $54^{\circ} \mathrm{C}\left(129.2^{\circ} \mathrm{F}\right)$. No distinct dose-response pattern was observed for either temperature or holding time.

\section{Discussion}

UNIFORMITY TESTS. Both the tests with the foam and the glass jars indicated the energy fields were neither uniform, constant in strength, nor consistent in location under the given conditions. A particular tendency was observed after many replicates, where the back row tended to be warmer, but could not be reproduced with reliability. Thus, it was difficult to correct for the lack of uniformity by adjusting or compensating the system. The range of variability in temperatures, even within short distances, was problematic.

Submerging the fruit and circulating them in the water may have reduced the effects of nonuniformity. Ikediala et al. (2002) recommended full immersion of fruit to improve temperature distribution. Birla et al. (2004) constructed a fruit mover for seven apples that reduced the standard deviation of stationary fruit of $9.6^{\circ} \mathrm{C}$ $\left(17.28^{\circ} \mathrm{F}\right)$ to $3.1^{\circ} \mathrm{C}\left(5.58^{\circ} \mathrm{F}\right)$ when fruit were rotated. However, unequal heating was prevalent throughout our tests, and fruit temperatures could not be duplicated following the same procedures. Deeper depths had consistently higher and less variable temperatures than shallower depths because of the low conductivity of the water and because of the center focusing effect of the near-spherical shape of the apples (Ikediala et al., 1999). This is advantageous because codling moth larvae feed in the interior of the fruit and because the heat-sensitive fruit surface has less thermal exposure than the conventional conduction methods of hot water, vapor heat, and forced hot air. Furthermore, the rate of heating was more consistent at the deeper depths. Yet, differences in temperature measurements at $1 \mathrm{~cm}$ in depth at the same site on the fruit were considerable, as much as $12.7^{\circ} \mathrm{C}\left(22.86^{\circ} \mathrm{F}\right)$, which has undesirable implications for both fruit quality and insect control. Temperature variations along the longitudinal axes and the latitudinal rings were random except for certain bruised areas that seemed more susceptible to heating and were often much warmer than adjoining healthy tissue.

For RF to work as a postharvest treatment, uniformity in the energy fields is essential (Ikediala et al., 1999). When fruit are heated unequally, their heating rates are also affected (Wang et al., 2003); warmer items may heat up faster, thus increasing the difference among temperatures. Obviously, this nonuniformity would preclude the commercial application for quarantine efficacy. Because apples are sensitive to heat (Neven and Drake, 2000; Neven et al., 2000), a reliable RF quarantine treatment would require a narrow range of temperatures with uniform heating at all sites, perhaps no more than $1^{\circ} \mathrm{C}\left(1.8^{\circ} \mathrm{F}\right)$ in variation. Commodities with a wider range of thermal tolerances would be better candidates than apples for future RF postharvest treatments.

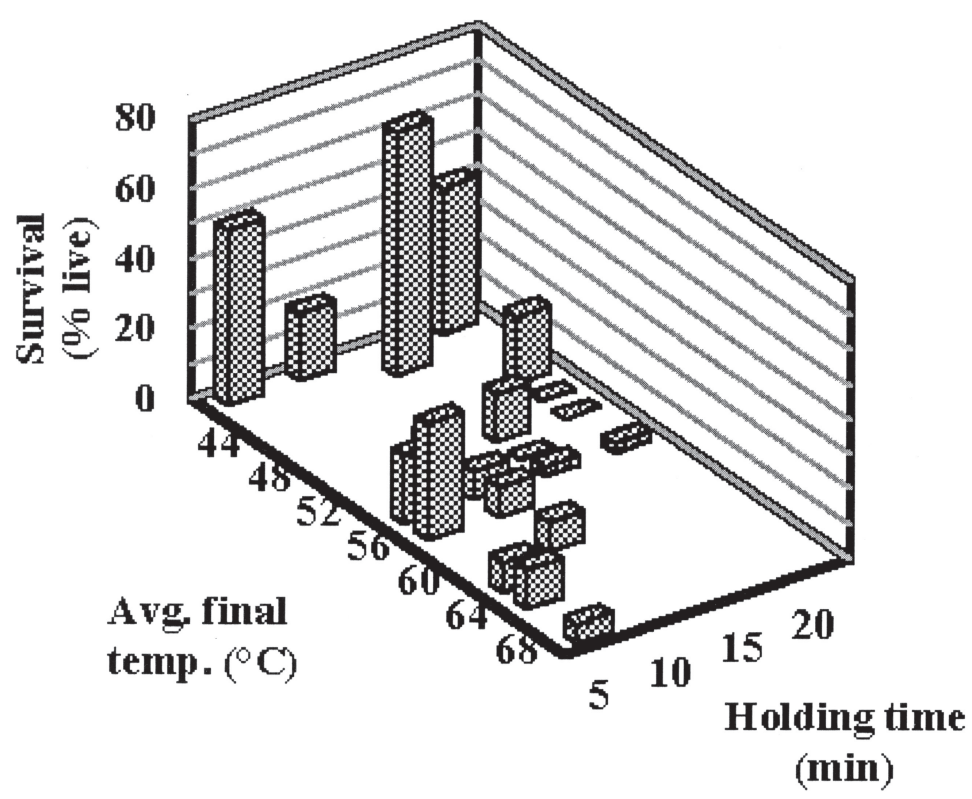

Fig. 2. Percent survival of codling moth larvae infesting nine apples (initial infestation rate of four larvae/fruit) after reaching a mean pulp temperature at $2 \mathrm{~cm}$ $(0.8$ inch $)$ depth and held for the specified times. ${ }^{\circ} \mathrm{F}=1.8\left({ }^{\circ} \mathrm{C}\right)+32^{\circ}$. 
Efricacy. To determine the efficacy of a treatment, it was necessary to use the average temperature at 2 $\mathrm{cm}$ to represent the temperature conditions in the fruit. This assumption ignored that temperatures were cooler near the fruit surface and that larvae could move within the fruit to more suitable locations. Regardless, appropriate efficacy was not obtained except at temperatures known to cause fruit damage (Neven et al., 1996, 2000). Holding the fruit in the RF-heated water seemed to increase efficacy, but the time was insufficient for quarantine security. Moving the fruit into a warm bath at $50{ }^{\circ} \mathrm{C}$ for a short period of time may increase the insect mortality. Longer holding periods would negate the advantage of the rapid heating by RF. Neven et al. (1996) reported that more than $100 \mathrm{~min}$ at $48^{\circ} \mathrm{C}(118.4$ ${ }^{\circ} \mathrm{F}$ ) vapor heat was needed to kill $99 \%$ of a population of fifth instar codling moth. However, retaining the fruit in the water bath would subject them to the same anaerobic conditions as the controlled-atmosphere thermal treatments (Neven and Mitcham, 1996) and would exploit the same advantages.

RF shows promise as a postharvest treatment because of its quickness, penetrating ability, and lack of undesirable residues. Its application to apples is problematic under the given conditions because: 1 ) heating is nonuniform; and 2 ) the length of thermal exposure required for quarantine security reduces fruit quality. If improvements can be developed to resolve these problems, it may become an effective replacement for methyl bromide. Because of its rapid rate of heating, RF may be better used in combination with other treatments.

\section{Literature cited}

Birla, S.L., S. Wang, J. Tang, and G. Hallman. 2004. Improving heating uniformity of fresh fruits in radio frequency treatments for pest control. Postharvest Biol. Technol. 33:205-217.

Hansen, J.D., S.R. Drake, H.R. Moffitt, J.L. Robertson, D.J. Albano, and M.L. Heidt. 2000. A two-component quarantine treatment for posthavest control of codling moth on apple cultivars intended for ex- port to Japan and Korea. HortTechnology 10:186-194.

Headlee, T.J. and D.M. Jobbins. 1936. Further studies of the use of radio waves in insect control. J. Econ. Entomol. 29:181-187.

Ikediala, J.N., J. Tang, L.G. Neven, and S.R. Drake. 1999. Quarantine treatment of cherries using $915 \mathrm{MHz}$ microwaves: Temperature mapping, codling moth mortality and fruit quality. Postharvest Biol. Technol. 16:127-137.

Ikediala, J.N., J.D. Hansen, J. Tang, S.R. Drake, and S. Wang. 2002. Development of saline water immersion technique with RF energy as a postharvest treatment against codling moth in cherries. Postharvest Biol. Technol. 24:25-37.

Jones, V.M. and B.C. Waddell. 1997. Hot-water effect on mortality of Cydia pomonella (Lepidoptera: Tortricidae). J. Econ. Entomol. 90:1357-1359.

Ministry of Agriculture, Forestry and Fisheries-Japan. 1950. Plant protection law enforcement regulations. Ministerial Ord. No. 73, Annexed Table 1. Tokyo.

Moffitt, H.R, S.R. Drake, and C.R. Sell. 1988. A two-component treatment for postharvest control on 'Red Delicious' and Golden Delicious' apples. Rpt. USDAARS-NPS, Yakima, Wash.

Neven, L.G. 1994. Combined heat treatments and cold storage effects on mortality of fifth-instar codling moth (Lepidoptera: Tortricidae). J. Econ. Entomol. 87:1262-1265.

Neven, L.G. and S.R. Drake. 2000. Comparison of alternative postharvest quarantine treatments for sweet cherries. Postharvest. Biol. Technol. 20:107-114.

Neven, L.G., S.R. Drake, and H.J. Ferguson. 2000. Effects of the rate of heating on apple and pear fruit quality. J. Food Qual. 23:17-325.

Neven, L.G. and E.J. Mitcham. 1996. CATTS (Controlled atmosphere/temperature treatment system): A novel tool for the development of quarantine treatments. Amer. Entomol. 42:56-59.

Neven, L.G., L.M. Rehfield, and K.C. Shellie. 1996. Moist and vapor forced air treatment of apples and pears: Effects on the mortality of fifth instar codling moth (Lepidoptera: Tortricidae). J. Econ. Entoml. 89:700-704.
Tang, J., J.N. Ikediala, S. Wang, J.D. Hansen, and R. Cavalieri. 2000. Hightemperature-short-time thermal quarantine methods. Postharvest Biol. Technol. 21:129-145.

Toba, H.H. and J.F. Howell. 1991. An improved system for mass-rearing codling moths. J. Entomol. Soc. Brit. Columbia $88: 2-27$.

United Nations Environmental Program. 1995. Montreal protocol on substances that deplete the ozone layer. Rpt. of Methyl Bromide Tech. Options Committee: 1995 assessment, Ozone Secretariat, Nairobi, Kenya.

U.S. Congress. 1990. A bill to amend the Clean Air Act to provide for attainment and maintenance of health protective national ambient air quality standards, and for other purposes. Clean Air Act Amendments of 1990, Public Law 101-549. Washington, D.C.

Wang, S., J.N. Ikediala, J. Tang, J.D. Hansen, E. Mitcham, R. Mao, and B. Swanson. 2001. Radio frequency treatments to control codling moth in in-shell walnuts. Postharvest Biol. Technol. 22:29-38.

Wang, S., J.N. Ikediala, J. Tang, and J.D. Hansen. 2002a. Thermal death kinetics and heating rate effects for fifth-instar Cydia pomonella (L.) (Lepidoptera: Tortricidae). J. Stored Prod. Res. 38:441-453.

Wang, S., J. Tang, J.A. Johnson, E. Mitcham, J.D. Hansen, R.P. Cavalieri, J. Bower, and B. Biasi. 2002b. Process protocols based on radio frequency energy to control field and storage pests in in-shell walnuts. Postharvest Biol. Technol. 26:29-38.

Wang, S., J. Tang, J.A. Johnson, E. Mitcham, J.D. Hansen, G. Hallman, S.R. Drake, and Y. Wang. 2003. Dielectric properties of fruits and insect pests as related to radio frequency and microwave treatments. Biosystems Eng. 85:201-212.

Yokoyama, V.Y., G.T. Miller, and R.V. Dowell. 1991. Response of codling moth (Lepidoptera: Tortricidae) to high temperature, a potential quarantine treatment for exported commodities. J. Econ. Entomol. 84:528-531.

Zolman, J.F. 1993. Biostatistics: Experimental design and statistical inference. Oxford Univ. Press, New York. 